\title{
Author Correction: Stress fibres are embedded in a contractile cortical network
}

Timothée Vignaud (D), Calina Copos, Christophe Leterrier (D), Mauricio Toro-Nahuelpan, Qingzong Tseng, Julia Mahamid (D), Laurent Blanchoin (1), Alex Mogilner (D), Manuel Théry 10 and Laetitia Kurzawa (i)

Correction to: Nature Materials https://doi.org/10.1038/s41563-020-00825-Z, published online 19 October 2020.

In the version of this Article originally published, ref. 60 was a duplicate of ref. 42. Ref. 60 should have been 'Engel, L. et al. Extracellular matrix micropatterning technology for whole cell cryogenic electron microscopy studies. J. Micromech. Microeng. 29, 115018 (2019).' This has now been corrected in all versions of the Article.

Published online: 30 October 2020

https://doi.org/10.1038/s41563-020-00862-8

๑) The Author(s), under exclusive licence to Springer Nature Limited 2020

\section{Author Correction: Stress fibres are embedded in a contractile cortical network}

Timothée Vignaud (D), Calina Copos, Christophe Leterrier (D, Mauricio Toro-Nahuelpan, Qingzong Tseng, Julia Mahamid (D,

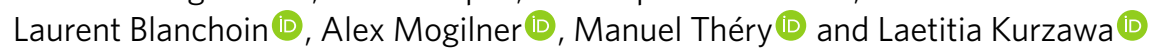

Correction to: Nature Materials https://doi.org/10.1038/s41563-020-00825-z, published online 19 October 2020.

In the version of this Article originally published, the label ' $k_{1}, \gamma_{1}$ ' at the top of Fig. $4 \mathrm{c}$ was incorrect; it should have read ' $k_{2}, \gamma_{2}$ ' This has now been corrected in all versions of the Article.

Published online: 18 November 2020

https://doi.org/10.1038/s41563-020-00874-4

( ) The Author(s), under exclusive licence to Springer Nature Limited 2020

\section{Author Correction: Mechanistic insights of evaporation-induced actuation in supramolecular crystals}

Roxana Piotrowska, Travis Hesketh (D), Haozhen Wang, Alan R. G. Martin, Deborah Bowering (D), Chunqiu Zhang,

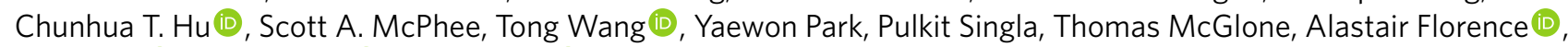
Tell Tuttle (1), Rein V. Ulijn (1D and Xi Chen (10)

Correction to: Nature Materials https://doi.org/10.1038/s41563-020-0799-0, published online 14 September 2020.

In the version of this Article originally published, Figs. 1 and 2 and Extended Data Fig. 3 contained some errors.

In Fig. $1 \mathrm{c}$,d,e the units of curvature in the $y$-axes were incorrect as $\mathrm{cm}^{-1}$; they should have been $\mathrm{mm}^{-1}$. In addition, in Fig. $1 \mathrm{~d}$ the right $y$-axis tick marks should have been labelled $1.0,0.8,0.6,0.4,0.2,0$ from bottom to top instead of $0,0.2,0.4,0.6,0.8,1.0$.

In Fig. $2 \mathrm{~b}, \mathrm{c}$ the left $y$-axis labels were missing a minus sign and should have been $-\Delta h(\mathrm{~nm})$. In addition, in Fig. $2 \mathrm{~b}$ the right $y$-axis tick mark labels 10 and 90 were mistakenly swapped; the labels should have been 90, 10 from bottom to top instead of 10, 90. Finally, in the caption of Fig. 2a the scale bar was mistakenly given as $2 \mathrm{~mm}$; it should have been $1 \mu \mathrm{m}$.

In the caption of Extended Data Fig. $3 \mathrm{f}$ the scale bar was mistakenly given as $500 \mathrm{~nm}$; it should have been $2 \mu \mathrm{m}$.

These errors have now been corrected.

Published online: 8 February 2021

https://doi.org/10.1038/s41563-021-00950-3

(C) The Author(s), under exclusive licence to Springer Nature Limited 2021 